Ophthalmologica

\title{
The Survival of Donor-Derived Cells in a Successfully Grafted Corneal Button 10 Years after Penetrating Keratoplasty for Lattice Dystrophy
}

\author{
Sun Woong Kim ${ }^{a, b}$ Hwan Young Lee ${ }^{d}$ Tae-im Kim ${ }^{b, c}$ Kyoung-Jin Shin ${ }^{d}$ \\ Woo Ick Yang ${ }^{\text {b, d }}$ Eung Kweon Kim ${ }^{\text {b, c }}$ \\ a Department of Ophthalmology, Soonchunhyang University College of Medicine, Soonchunhyang University \\ Bucheon Hospital, Bucheon, ${ }^{b}$ Department of Medicine, Graduate School of Yonsei University, ${ }^{c}$ Corneal Dystrophy \\ Research Institute, Department of Ophthalmology, Yonsei University College of Medicine, and d Department of \\ Forensic Medicine, Yonsei University College of Medicine, Seoul, Korea
}

\section{Key Words}

Cornea transplantation $\cdot$ Keratocytes $\cdot$ Keratoplasty $\cdot$

Lattice corneal dystrophy $\cdot$ Recurrence of corneal dystrophy

\begin{abstract}
Aims: To investigate the survival of donor-derived cells in a successfully grafted corneal button 10 years after penetrating keratoplasty for lattice dystrophy. Methods: In 1996, a 48-year-old male with lattice corneal dystrophy underwent penetrating keratoplasty 3 times in the right eye within a 3month interval. Nine years and 7 months later, the patient underwent a fourth penetrating keratoplasty. After surgery, the previous graft was analyzed to determine the origin of the cells. The epithelium and endothelium were removed, and then the button was dissected into 5 stromal blocks measuring $2 \times 1.8 \mathrm{~mm}$. Tissues underwent forensic genotyping using 16 markers (amelogenin for sex chromosomes and 15 autosomal short tandem repeats). Patient buccal tissue DNA was used as a control. Results: The epithelium and buccal tissue contained identical DNA (i.e. recipient DNA). Similarly, the most peripheral stromal tissue contained only recipient DNA. In contrast, the most central stromal tissue
\end{abstract}

only contained DNA of nonrecipient origin (presumably donor), while the stromal tissue between the periphery and center contained both recipient and nonrecipient DNA. Conclusions: The corneal stroma was infiltrated by surrounding recipient-derived keratocytes from the periphery. Therefore, more donor-derived cells had survived in the central stroma.

Copyright $\odot 2009$ S. Karger AG, Basel

\section{Introduction}

The fate of corneal transplant cells has been a topic of controversy from the early days of keratoplasty. In the 1970s, Barr body identification in sex-mismatched corneal transplants was used in such studies, but this method only allows determination of the statistical probability of the gender of a piece of tissue $[1,2]$. The introduction of fluorescence in situ hybridization (FISH) analysis of sex chromosomes in ocular tissue is a major development in transplanted corneal cell fate studies. FISH is very specific and can identify sex chromosomes in individual cells of all cell types present in the eye without destroying the ocular texture $[3,4]$. However, FISH is a rel-

\section{KARGER}

Fax +4161306 1234

E-Mail karger@karger.ch

www.karger.com (c) 2009 S. Karger AG, Basel

0030-3755/09/2236-0396\$26.00/0

Accessible online at:

www.karger.com/oph
E.K. Kim, MD, PhD

Department of Ophthalmology, Yonsei University College of Medicine

Seodaemoongu Shinchondong 134

CPO Box 8044, Seoul (Korea)

Tel. +822 2228 3570, Fax +822 312 0541, E-Mail eungkkim@yuhs.ac 


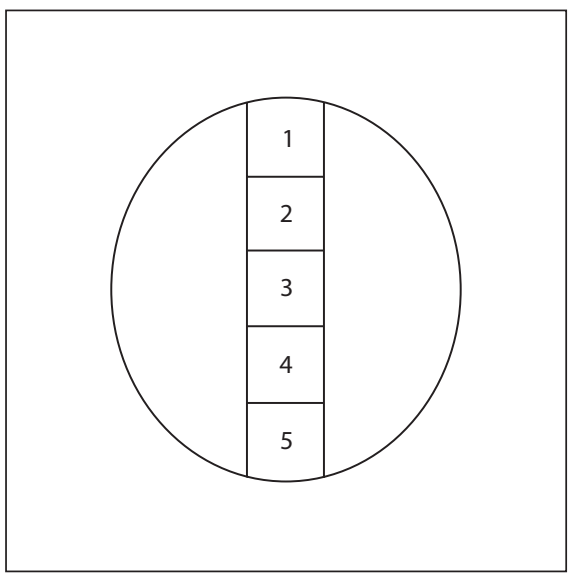

Fig. 1. Schematic diagram illustrating the preparation of the cornea button. The epithelium was peeled from the cornea button. The remaining stroma was dissected into 5 blocks of $1.8 \times 2 \mathrm{~mm}$ (samples No. 1-5). Tissue in each block underwent DNA genotyping to determine the source of the cells.

atively time-consuming process and can be applied only to sex-mismatched cases.

The present study investigated donor cell replacement by recipient cells in a corneal graft using a forensic genotyping technique [5]. In contrast to earlier studies [1-4, 6-8], this approach allowed identification of the distribution of donor cells in the cornea. Moreover, this method is not limited to sex-mismatched cases.

\section{Case Report}

\section{Patient Information}

A 48-year-old male patient presented at our clinic in November 1995 with lattice corneal dystrophy and a visual acuity of 5/200 in both eyes. In September 1996, the patient underwent penetrating keratoplasty on the right eye twice within 3 weeks at another clinic. Two months later, the patient presented again at our clinic complaining of decreased vision in the right eye. Our slitlamp examination suggested graft rejection. Topical and systemic steroid treatment was commenced but failed to rescue the graft. In December 1996, we performed a third penetrating keratoplasty. Due to the eccentric previous graft and anterior synechia in the periphery ranging at $120^{\circ}$ (4- to 8-o'clock position), we performed a large keratoplasty after synechiolysis, with a donor size of $9.0 \mathrm{~mm}$ and a recipient bed of $8.5 \mathrm{~mm}$. Vision recovered to 0.3 by 2 weeks postoperatively and remained steady until September 2005. There were 5 minor rejection reactions during this time in the right cornea, and these were controlled using steroids. During follow-up, the superior half of the right cornea became cloudy, and the endothelial cell count was 485 . However, there was no clinical evidence of lattice lesion recurrence. In July 2006, a fourth penetrating keratoplasty was performed using a similarly sized graft as for the third procedure. At the time of the fourth penetrating keratoplasty, the previous graft was removed and analyzed to investigate whether donor-derived cells were still present. This study was approved by the Severance Hospital IRB Committee.

Methods for Harvesting Tissues and DNA Analysis

The previously grafted corneal button was removed from the host cornea using forceps, with the epithelium and stroma removed en block, while leaving Descemet's membrane and endothelium still attached to the recipient side. The epithelium was carefully harvested into a specimen tube using a Bard-Parker No. $15 \mathrm{knife}$. The central stroma measuring $2.0 \mathrm{~mm}$ in width and $9 \mathrm{~mm}$ in length was excised from the whole stroma and was then dissected into 5 blocks, numbered 1 at the 12 o'clock position, 3 at the center and 5 at the 6 o'clock position (fig. 1). An endothelium sample was not taken for testing as the tissue had been exposed to blood in the anterior chamber during synechiolysis. The buccal mucosa of the patient was harvested using a cotton swab as a control of recipient DNA. The epithelium, stroma samples No. 1-5 and the buccal mucosa underwent forensic genotyping analysis to determine if the tissues contained recipient and/or nonrecipient (i.e. donor) DNA. DNA was extracted using a DNA $\mathrm{IQ}^{\mathrm{TM}}$ system (Promega Co., Madison, Wisc., USA) according to the manufacturer's instructions. The Powerplex 16 system kit (Promega Co.) was used, and 16 genotype markers were tested for amelogenin for sex chromosomes and 15 autosomal short tandem repeats.

\section{Results}

The DNA in the epithelium sample was found to be identical to that in the recipient buccal control sample, indicating that the epithelial cells were all derived from the recipient. Similarly, the DNA in stroma sample No. 1 (the most superior stromal level) was identical to the recipient control. In contrast, the DNA from stroma sample No. 3 (the central block) was different from that of the recipient. The DNA in stroma samples No. 2, 4 and 5 showed both recipient and nonrecipient genotypes (fig. 2, table 1).

\section{Discussion}

The present study examined whether donor-derived cells remained present in a corneal graft after nearly 10 years. The results showed that all donor epithelial cells were replaced by recipient cells, while stromal cells appeared to be derived from both recipient and nonrecipient sources. In the present case, the nonrecipient source was presumably the donor since the analysis involved 16 different markers and the pattern of each marker was 
Fig. 2. Electropherogram of 5 tetramethylrhodamine-5-maleimide-labeled loci: amelogenin, vWA, D8S1179, TPOX and FGA. Note the identical patterns for the samples of recipient buccal DNA (control), epithelium and stroma sample No. 1 . Note that stroma sample No. 3 has a unique profile indicating that it does not contain recipient DNA. Note that stroma samples No. 2, 4 and 5 have profiles suggesting both recipient and nonrecipient DNA. Note that the major peaks in stroma sample No. 5 correlate with recipient DNA. The other 11 loci showed similar patterns.

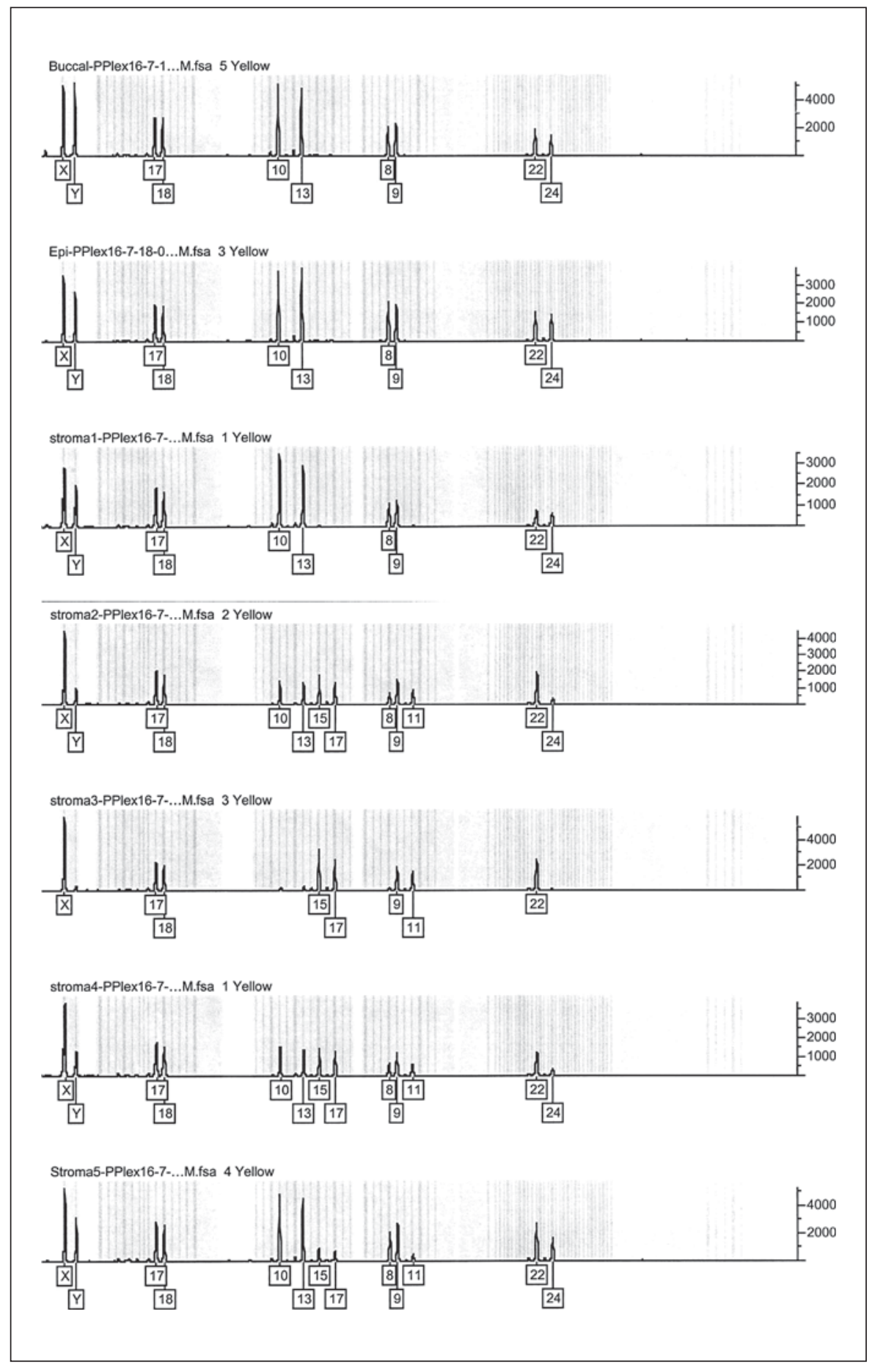

highly consistent in each specimen. Such marker data indicate that the findings are highly unlikely to be the result of sample contamination. Interestingly, in terms of the stroma, cell derivation appeared to be a function of stromal position. Donor-derived cells were preserved in the center of the stroma, while the midperipheral stroma contained both recipient and donor-derived cells, and the stroma periphery contained only recipient cells. These findings suggest that donor cells were progressively replaced by recipient cells from the periphery. 
Table 1. Observed alleles following genotyping using the Powerplex 16 system

\begin{tabular}{|c|c|c|c|c|c|c|c|}
\hline Locus & Buccal & Epithelium & Stroma 1 & Stroma 2 & Stroma 3 & Stroma 4 & Stroma 5 \\
\hline D3S1358 & $15-15$ & $15-15$ & $15-15$ & $15-15$ & $15-15$ & $15-15$ & $15-15$ \\
\hline TH01 & $8-9$ & $8-9$ & $8-9$ & $8-9$ & $9-9$ & $8-9$ & $8-9$ \\
\hline D21S11 & $30-30$ & $30-30$ & $30-30$ & $30-31.2$ & $30-31.2$ & $30-31.2$ & $30-31.2$ \\
\hline D18S51 & $15-19$ & $15-19$ & $15-19$ & $12-14-15-19$ & $12-14$ & $12-14-15-19$ & $12-14-15-19$ \\
\hline Penta E & $10-17$ & $10-17$ & $10-17$ & $10-17-18$ & $10-18$ & $10-17-18$ & $10-17-18$ \\
\hline D5S818 & $11-12$ & $11-12$ & $11-12$ & $9-11-12$ & $9-9$ & $9-11-12$ & $9-11-12$ \\
\hline D13S317 & $7-11$ & $7-11$ & $7-11$ & $7-11$ & $11-11$ & $7-11$ & $7-11$ \\
\hline D7S820 & $11-13$ & $11-13$ & $11-13$ & $10-11-12-13$ & $10-12$ & $10-11-12-13$ & $10-11-12-13$ \\
\hline D16S539 & $9-10$ & $9-10$ & $9-10$ & $9-10-11$ & $9-11$ & $9-10-11$ & $9-10-11$ \\
\hline CSF1PO & $12-12$ & $12-12$ & $12-12$ & $10-12$ & $10-10$ & $10-12$ & $10-12$ \\
\hline Penta D & $9-14$ & $9-14$ & $9-14$ & $9-10-14$ & $9-10$ & 9-10-14 & 9-10-14 \\
\hline Amel. & $\mathrm{X}-\mathrm{Y}$ & $X-Y$ & $\mathrm{X}-\mathrm{Y}$ & $X-Y$ & $\mathrm{X}-\mathrm{X}$ & $X-Y$ & $\mathrm{X}-\mathrm{Y}$ \\
\hline vWA & $17-18$ & $17-18$ & $17-18$ & $17-18$ & $17-18$ & $17-18$ & $17-18$ \\
\hline D8S1179 & $10-13$ & $10-13$ & $10-13$ & $10-13-15-17$ & $15-17$ & $10-13-15-17$ & $10-13-15-17$ \\
\hline TPOX & $8-9$ & $8-9$ & $8-9$ & 8-9-11 & $9-11$ & 8-9-11 & 8-9-11 \\
\hline FGA & $22-24$ & $22-24$ & $22-24$ & $22-24$ & $22-22$ & $22-24$ & $22-24$ \\
\hline
\end{tabular}

Buccal = Buccal mucosa; amel. $=$ amelogenin; dominant alleles are shown in italics .

The present findings are consistent with those of others. Wollensak and Green [3] used FISH analysis of sex chromosomes in sex-mismatched corneal transplants to distinguish between host and donor cells. They found complete replacement of donor cells in 11 of 14 corneal buttons ranging from 11 months to 30 years postoperatively. However, in 3 cases they found that $15-26 \%$ of keratocytes were donor derived at 2.5, 2.6 and 4.5 years postoperatively. They reported that the surviving stromal keratocytes were present in small groups of 2-4 cells distributed throughout the corneal stroma rather than localized in specific areas. Basu and Carre [1] observed stromal keratocyte replacement as early as 6 months postoperatively, and a maximum survival time of 6 years for donor cells.

The present study shows that donor-derived cells remained for approximately 10 years, and this is the first demonstration of such long-term survival in a corneal graft. It is probable that the extent and timing of donor cell replacement is influenced by individual case features such as graft rejection or corneal edema. Hori and Streilein [9] found that donor-derived keratocytes and endothelial cells persisted to a high level in accepted corneal allografts in mice, and were eliminated when grafts were rejected. In the present case, the patient had a clear inferior half and an edematous superior half of the cornea. This clinical finding is consistent with the genotyp- ing data showing no donor-derived cells in stroma sample No. 1, and both donor-derived and recipient cells in sample No. 5. These data support the view that an accepted corneal graft retains more donor-derived cells.

The current case differs from previous reports [10] in that the lattice dystrophy had not recurred after approximately 10 years. The basis of lattice dystrophy recurrence remains unknown. The present work is consistent with the view that infiltrating stromal keratocytes would be related to such a recurrence, since the lack of recurrence in the present case may be due to fewer surrounding recipient keratocytes as a result of a relatively large removal of tissue $(9.0 \mathrm{~mm})$. If epithelial cells play a major role in producing abnormal proteins in lattice dystrophy, recurrence could occur in the early postoperative period even after a successful transplantation. Alternatively, it may be that a close interaction between epithelial cells and keratocytes is required for lattice-like lesion development. We propose that fewer surrounding peripheral keratocytes in a large graft means it takes longer to completely replace the donor cells compared to a small graft, and that this could be a factor relevant to the absence of the recurrence in this case. Further studies are required to determine whether replacement progresses more rapidly in a small graft.

In conclusion, the present study describes a case of donor-derived cells in the central stromal area nearly 10 
years after a large corneal graft. This long-term survival of donor-derived cells may explain the absence of lattice lesion recurrence. In addition, the present study suggests that forensic DNA analysis is an easy and sensitive way to investigate the fate of corneal cells after transplantation. The present findings indicate that a similar study using a large case series is warranted.

\section{Acknowledgements}

This work was supported by a Korea Science and Engineering Foundation (KOSEF) grant funded by the Korean government (MOST) (No. R11-2007-040-02002-0), and by a National Research Foundation of Korea (NRF) grant funded by the Korean government (MEST) (No. M1AQ19, 2009-0082186).

\section{References}

1 Basu PK, Carre F: A study of cells in human corneal grafts. Can J Ophthalmol 1973;8: $1-7$.

-2 Kinoshita S, Friend J, Thoft RA: Sex chromatin of donor corneal epithelium in rabbits. Invest Ophthalmol Vis Sci 1981;21:434441.

-3 Wollensak G, Green WR: Analysis of sexmismatched human corneal transplants by fluorescence in situ hybridization of the sex chromosomes. Exp Eye Res 1999;68:341346.

4 Wollensak G, Perlman EJ, Green WR: Interphase fluorescence in situ hybridization of the $\mathrm{X}$ and $\mathrm{Y}$ chromosomes in the human eye. Br J Ophthalmol 2001;85:1244-1247.
5 Moretti TR, Baumstark AL, Defenbaugh DA, Keys KM, Smerick JB, Budowle B: Validation of short tandem repeats (STRs) for forensic usage: performance testing of fluorescent multiplex STR systems and analysis of authentic and simulated forensic samples. J Forens Sci 2001;46:647-660.

6 Khodadust AA, Silverstein AM: The survival and rejection of epithelium in experimental corneal transplants. Invest Ophthalmo Vis Sci 1969;8:169-179.

7 Khodadust AA, Silverstein AM: Transplantation and rejection of individual cell layers of the cornea. Invest Ophthalmol Vis Sci 1969;8:180-195.
-8 Egarth M, Hellkvist J, Claesson M, Hanson C, Stenevi U: Longterm survival of transplanted human corneal epithelial cells and corneal stem cells. Acta Ophthalmol Scand 2005;83:456-461.

-9 Hori J, Streilein JW: Dynamics of donor cell persistence and recipient cell replacement in orthotopic corneal allografts in mice. Invest Ophthalmol Vis Sci 2001;42:1820-1828.

10 Klintworth GK, Ferry AP, Sugar A, Reed J: Recurrence of lattice corneal dystrophy type I in the corneal grafts of two siblings. Am J Ophthalmol 1982;94:540-546. 